\title{
Mechanochemical Solid-Phase Reaction between Polyvinylidene Fluoride and Sodium Hydroxide
}

\author{
QIWU ZHANG, ${ }^{1}$ JINFENG LU, ${ }^{1}$ FUMIO SAITO, ${ }^{1}$ MICHEL BARON ${ }^{2}$ \\ ${ }^{1}$ Institute of Multidisciplinary Research for Advanced Materials, Tohoku University, 2-1-1, Katahira, Aoba-ku, \\ Sendai 980-8577, Japan \\ ${ }^{2}$ Ecole des Mines d Albi, 81013 Albi Cedex 09, France
}

\begin{abstract}
Grinding a mixture of polyvinylidene fluoride (PVDF) and $\mathrm{NaOH}$ was conducted by a planetary ball mill at atmospheric condition to investigate mechanochemical reaction between the two substances. The grinding stimulates the reaction to form $\mathrm{NaF}$ and organic composites. Yield of fluorine converted from PVDF to NaF increases with an increase in grinding time and reaches $90 \%$ at 60 min or more. As for the organic phase, oxygen-bearing compounds are formed due to substitution of fluorine by $\mathrm{OH}$ base. The organic compounds are classified into water-soluble and insoluble ones, depending on their structures.
\end{abstract}

Key words: PVDF; grinding; mechanochemical reaction; defluorination

\section{INTRODUCTION}

Polyvinylidene fluoride ( $\mathrm{PVDF},\left[\mathrm{CH}_{2} \mathrm{CF}_{2}\right]_{\mathrm{n}}$ ) is one of the fluorine resin group, and is distinguished by excellent resistance to heat, aging and abrasion, chemical stability with nontoxicity, unique electrical properties, durability for UV, and gamma radiation. These properties allow us to use it in a wide range such as mechanical, chemical, electrical, agricultural, and food industries. ${ }^{1,2}$ Recently, the amount of fluorine resin produced has increased; accordingly, so has the amount of the waste resin been growing. When the waste halogen-bearing resins ${ }^{3-6}$ are burned in a furnace, toxic gases such as HF as well as harmful substances like dioxins are emitted in a flue gas and ashes. Because the emission of such toxic and harmful substances should be prevented, proper techniques are

Correspondence to: Q. Zhang. strongly required in waste deposit facilities. A method for adsorbing toxic gases in a thermal treatment of the waste has been developed; however, this is sometimes accompanied with corrosion of devices for adsorbing the gases.

Another route for processing such polymer wastes is a mechanochemical method. ${ }^{7-9} \mathrm{Al}-$ though it is known that mechanical treatment of polymer will degrade it easily and its molecular weight decreases to a relatively low level, ${ }^{10-13}$ the basic unit (monomer part) remains unchanged after the mechanical treatment. It is different in the mechanochemical process where an active chemical is added into polymer so that not only degradation but a real reaction takes place. In this article, we provide fundamental information on the mechanochemical solid phase reaction between PVDF and $\mathrm{NaOH}$ to form organic compounds and $\mathrm{NaF}$. The organic phases after defluorination may be used as fuel, while $\mathrm{NaF}$ has a possibility to be a source for fluorine recycling. 


\section{EXPERIMENTAL}

The PVDF sample (called sample A) used in the experiment was supplied from Dowa Mining Co. Ltd., Japan. $\mathrm{NaOH}, \mathrm{HCl}$ solution, and ethyl acetate were obtained from Wako Pure Chemical Industries, Ltd., Japan. The PVDF and $\mathrm{NaOH}$ samples were mixed as a starting mixture where fluorine is equivalent to sodium in the starting mixture.

A planetary ball mill (Pulverisette-7, Fritsch, Germany) was used to grind the starting mixtures at approximately $700 \mathrm{rpm}$ under atmospheric condition. Four grams of the mixture were charged in a zirconia pot of $45 \mathrm{~cm}^{3}$ inner volume with seven zirconia balls of $15 \mathrm{~mm}$ diameter and ground for different periods of time.

Washing operation for the ground samples was conducted as follows: $1 \mathrm{~g}$ of sample was dispersed into $50 \mathrm{~mL}$ distilled water in a vial with mechanically agitation for $60 \mathrm{~min}$. Subsequently, the suspension was filtered to separate solid and liquid phases. The solid particles were rinsed with 50 $\mathrm{mL}$ distilled water two times. The solid particles was called sample B. $\mathrm{pH}$ value of the filtrate was regulated to 2 by adding $\mathrm{HCl}$ solution, then $40 \mathrm{~mL}$ ethyl acetate was added to the filtrate of $250 \mathrm{~mL}$ to extract soluble organic phase. The organic sample after the extraction is called sample C. Both samples $\mathrm{B}$ and $\mathrm{C}$ were dried at $373 \mathrm{~K}$ for $2 \mathrm{~h}$ in air.

$\mathrm{X}$-ray diffraction (XRD) analysis was conducted on the ground samples for identifying phases in the

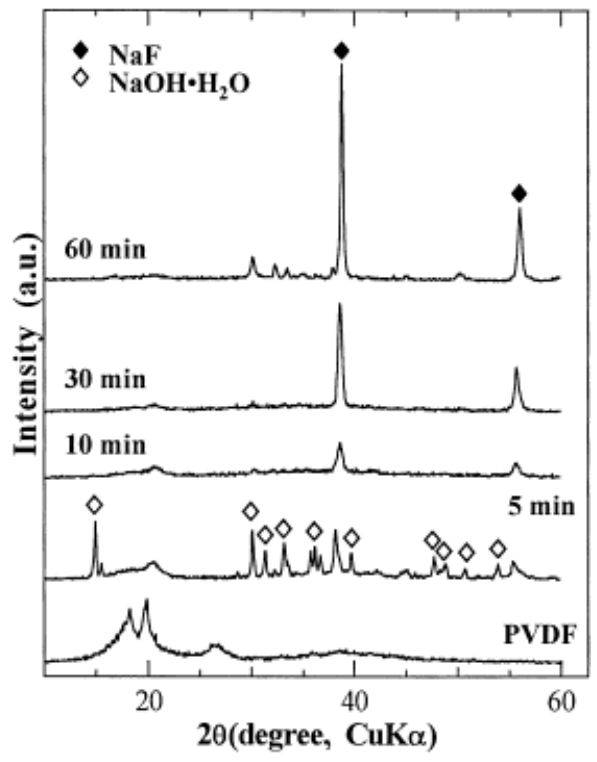

Figure 1 XRD patterns of the PVDF and $\mathrm{NaOH}$ mixture ground for different periods of time.

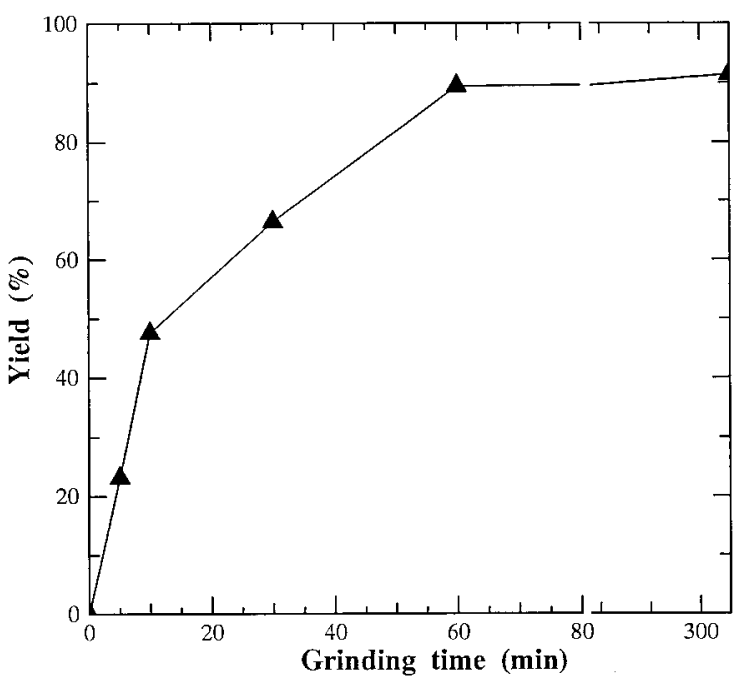

Figure 2 Yield of the $\mathrm{F}$ extracted by washing the ground mixture.

ground samples. $\mathrm{Mg}-\mathrm{K} \alpha$ radiation was used in $\mathrm{X}$ ray photoelectron spectroscopic (XPS) measurement to record spectra for samples A, B, and C. Infrared spectra for these three samples were recorded by means of Fourier transform infrared (FTIR) spectroscopy using a KBr disc method. Fluorine concentration in the filtrate was measured by an Ion-Chromatography (IC) method.

\section{RESULTS}

Figure 1 shows XRD patterns of the original PVDF and the mixtures ground for different periods of time. Peaks of $\mathrm{NaF}$ are observed in the pattern of the sample ground for $10 \mathrm{~min}$. Intensity of the peak increases relatively with an increase in grinding time. The result suggests that displacement reaction of fluoride anion for $\mathrm{OH}$ base proceeds during the grinding to form $\mathrm{NaF}$ in the product, although no clear information on dissociation of organic compounds is provided.

Because the reaction product, $\mathrm{NaF}$, is soluble in water, conversion of fluorine from PVDF into $\mathrm{NaF}$ can be easily obtained by measuring its fluorine concentration in the filtrate after washing operation. Figure 2 shows yield of fluorine converted from the PVDF sample as a function of grinding time. The yield increases rapidly in the early stage of grinding to about $50 \%$ at $10 \mathrm{~min}$, and then rises gradually to about $90 \%$ at $60 \mathrm{~min}$. However, no further significant improvement in the yield can be made. 


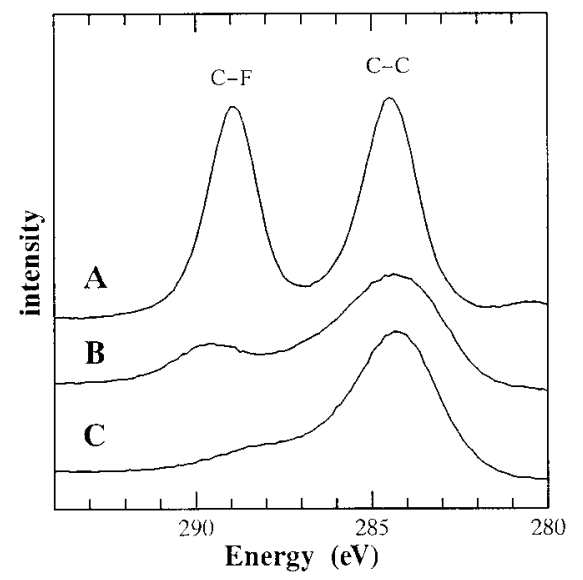

Figure 3 XPS spectra of the C1s of samples A, B, and $\mathrm{C}$.

Figure 3 shows C1s spectra of samples A, B, and $\mathrm{C}$. The spectrum for sample $\mathrm{A}$ gives two peaks due to the existence of $\mathrm{C}-\mathrm{C}$ and $\mathrm{C}-\mathrm{F}$ bindings in the sample. The peak due to $\mathrm{C}-\mathrm{F}$ binding at higher binding energy broadens and weakens significantly for sample B, and it almost disappears for sample $\mathrm{C}$. These results indicate that $\mathrm{C}-\mathrm{F}$ binding has been cut off, and the defluorination of PVDF has been achieved.

Figure 4 shows the $01 \mathrm{~s}$ spectra of samples B and C. It is interesting to notice that oxygen exists in both samples $\mathrm{B}$ and $\mathrm{C}$, and the peak intensity in sample $\mathrm{C}$ is much higher than that in sample B. Because oxygen does not exist in the original PVDF, the oxygen in samples $\mathrm{B}$ and $\mathrm{C}$ should come from $\mathrm{NaOH}$ through the mechanochemical reaction. The water-soluble sample $\mathrm{C}$ has a much higher amount of oxygen than the insoluble sample B.

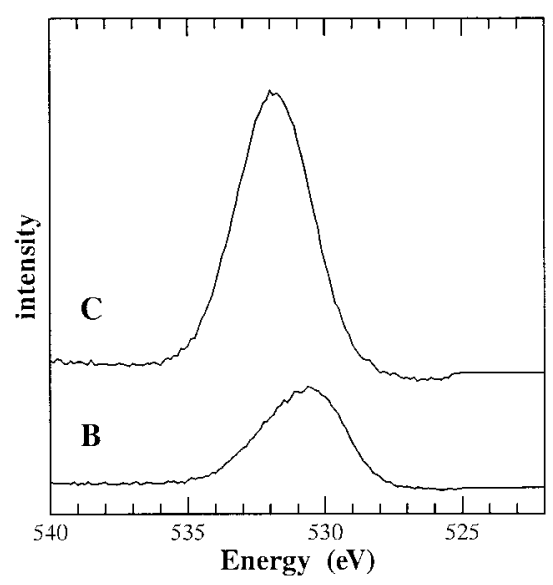

Figure 4 XPS spectra of the O1s of the samples.

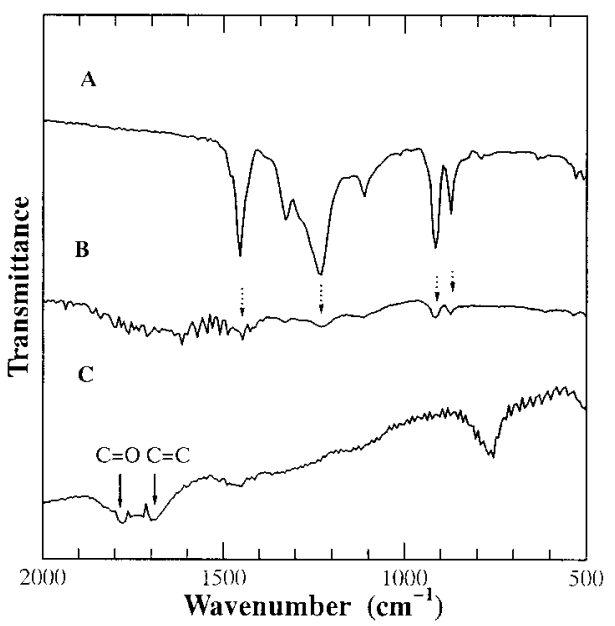

Figure 5 FTIR spectra of samples A, B, and C.

Figure 5 shows FTIR spectra of samples A, B, and C. Compared with the pattern of sample A (original PVDF sample), visible peaks in the spectrum of sample B are the same as that of PVDF. The intensity of the peaks has reduced significantly. This indicates that a small amount of unreacted PVDF is left in sample $B$. As for the pattern of sample $\mathrm{C}$, three new broadened peaks are observed. Combined with the information from XPS, the new peaks could be understood as follows: the peak at about $1700-1800 \mathrm{~cm}^{-1}$ comes from carbonyl $(\mathrm{C}=\mathrm{O})$ stretch vibration, and the peak around $1600-1700 \mathrm{~cm}^{-1}$ may be related to the stretch vibration of the double carbon binding $(\mathrm{C}=\mathrm{C})$. As for the relatively large peak in the range between $700-800 \mathrm{~cm}^{-1}$, this may be due to the bending vibration of $\mathrm{C}=\mathrm{C}-\mathrm{H}$ binding.

\section{DISCUSSION}

The mechanochemical solid-phase reaction takes place through the substitution of $\mathrm{F}$ by the $\mathrm{OH}$ base to form a kind of alcohol, $\left[\mathrm{CH}_{2}-\mathrm{C}(\mathrm{OH})_{2}\right]$, as given by eqs. (1) and (2) expressed as a monomer unit reaction.

$$
\begin{aligned}
{\left[\mathrm{CH}_{2}-\mathrm{CF}_{2}\right]+\mathrm{NaOH} \rightarrow \mathrm{NaF} } & \\
+ & {\left[\mathrm{CH}_{2}-\mathrm{CF}(\mathrm{OH})\right] } \\
{\left[\mathrm{CH}_{2}-\mathrm{CF}(\mathrm{OH})\right]+\mathrm{NaOH} } & \rightarrow \mathrm{NaF} \\
& +\left[\mathrm{CH}_{2}-\mathrm{C}(\mathrm{OH})_{2}\right]
\end{aligned}
$$


It is deduced that the displacement reaction for half (one side linked to carbon) of the fluorine given by eq. (1) proceeds very easily because nearly $50 \%$ of the fluorine is converted into $\mathrm{NaF}$ within 10 min of grinding, as shown in Figure 2. The relatively slow increase in fluorine yield in Figure 2 suggests that it has become difficult to replace another half (opposite side linked to carbon) fluorine given by eq. (2). High moisture observed in the ground sample over $30 \mathrm{~min}$ indicates that dehydration of $\left[\mathrm{CH}_{2}-\mathrm{CF}(\mathrm{OH})\right]$ or $\left[\mathrm{CH}_{2}-\mathrm{C}(\mathrm{OH})_{2}\right]$ takes place with a progress of substitution reaction of $\mathrm{F}$ by the $\mathrm{OH}$ base as follows:

$$
\begin{gathered}
{\left[\mathrm{CH}_{2}-\mathrm{CF}(\mathrm{OH})\right] \rightarrow[\mathrm{CH}=\mathrm{CF}]+\mathrm{H}_{2} \mathrm{O}} \\
{\left[\mathrm{CH}_{2}-\mathrm{C}(\mathrm{OH})_{2}\right] \rightarrow\left[\mathrm{CH}_{2}-\mathrm{C}=\mathrm{O}\right]+\mathrm{H}_{2} \mathrm{O}}
\end{gathered}
$$

The formation of $\mathrm{H}_{2} \mathrm{O}$ in the ground sample causes strong agglomeration of the fine particles, which hinders the grinding efficiency so that further substitution of $\mathrm{F}$ by the $\mathrm{OH}$ base expressed as eq. (2) proceeds relatively slowly compared to eq. (1). This is the main reason why the prolonged grinding does not improve the reaction efficiently. If the water formed is taken out and the strong agglomeration is lightened, the grinding efficiency will be improved considerably to be able to give a nearly complete defluorination for the polymer. The proper method is under consideration.

The substitution of $\mathrm{F}$ by the $\mathrm{OH}$ base leads to binding of polar base to organic compound, and the dehydration leads to formation of carbon-rich organic phases. The former is a main composition of sample $\mathrm{C}$, and the later is that of sample $\mathrm{B}$. Sample B consists of the unreacted PVDF as well as the carbon-rich compounds. Sample $C$ is the compounds with various types of polar base like the $\mathrm{OH}$ base, carbonyl base $(\mathrm{C}=\mathrm{O})$. Therefore, the organic phase in the ground sample is not one pure compound with only one base, but a mixture consisting of different types of chemical bases.

\section{CONCLUSION}

Mechanochemical solid-phase reaction between $\mathrm{PVDF}$ and $\mathrm{NaOH}$ proceeds rapidly in the beginning of the grinding stage to convert nearly half of the fluorine in PVDF into NaF through the substitution of fluorine in PVDF by the $\mathrm{OH}$ base. The subsequent dehydration takes place to generate water molecules, which cause the strong agglomeration of the obtained fine particles, decreasing the speed of this substitution reaction. About $90 \%$ of fluorine in the PVDF sample can be converted into $\mathrm{NaF}$ by this process. This indicates a high possibility of recycling fluorine from waste PVDF polymers.

The authors are grateful to Mr. Choju Nagata, General Manager, Electric Materials Company, Magnetic Materials Business Unit, Dowa Mining Co. Ltd., for generously supplying the PVDF sample. They wish to thank the IFPRI Inc. for providing the financial support to carry out this work.

\section{REFERENCES}

1. Inderherbergh, J. Ferroelectrics 1991, 115, 295.

2. Duraud, J. P.; Le Moel, A.; Le Gressus, C. Radiat Effect 1986, 98, 151.

3. Tukuda, T. Shigen-Shori-Gijutsu 1999, 46, 187.

4. Yoshioka, T.; Furukawa, K.; Sato, T.; Okuwaki, A. J Appl Polym Sci 1998, 70, 129.

5. Winkler, D. E. J Polym Sci 1959, 35, 3.

6. Gupta, M. C.; Viswanath, S. C. Ind Eng Chem Res 1998, 37, 2707.

7. Loiselle, S.; Branca, M.; Mulas, G.; Cocco, G. Environ Sci Technol 1997, 31, 261.

8. Rowlands, S. A.; Hall, A. K.; McCormick, P. G.; Street, R.; Hart, R. J.; Ebell, G. F.; Donecker, P. Nature 1994, 367, 223.

9. Cao, G.; Doppiu, S.; Monagheddu, M.; Orru, R.; Sannia, M.; Cocco, G. Ind Eng Chem Res 1999, 38, 3218.

10. Watson, W. F.; Pike, M. J Polym Sci 1952, 9, 229.

11. Jellinek, H. H. G. J Polym Sci 1951, 6, 745.

12. Bestul, A. B. J Appl Phys 1953, 24, 1011.

13. Yasue, T.; Aizawa, T.; Arai, Y. Nippon-KakakuKaishi 1976, 3, 415. 